\title{
Los clíticos en Brasil: reivindicación literaria a través de Jorge Amado
}

\author{
Ignacio VÁZQUEZ DiÉGUEZ \\ Departamento de Filología Románica \\ Universidad de Barcelona \\ ivazquez@ub.edu
}

\begin{abstract}
RESUMEN
Desde una perspectiva sintáctica, la colocación de los pronombres átonos en la frase portuguesa presenta hoy dos posibilidades: la solución europea (normativa en África y Asia) y la americana. Lo que en principio fue una diferencia lingüística entre Portugal y Brasil pronto se convirtió en una cuestión nacional. Dignificar esa diferencia en la escritura, y particularmente en la literatura, suponía para la antigua colonia la emancipación. Jorge Amado fue uno de los escritores brasileños que ayudó en tal cometido.
\end{abstract}

Palabras clave: lingüística diacrónica, gramática, clíticos, lengua portuguesa

[Recibido, junio 2010; aprobado, diciembre 2010]

\section{Clitics in Brazil: literary demand through Jorge Amado}

\begin{abstract}
From a syntactic perspective, the position of object pronouns in Portuguese speech today offers two possibilities: the European use (compulsory in Africa and Asia) and the American one. What began as a linguistic difference between Portugal and Brazil became a national issue. Dignifying that difference in writing -especially in literature- meant emancipation for the former colony (Brazil). Brazilian writer Jorge Amado helped to achieve this.
\end{abstract}

Keywords: diachronic linguistics, grammar, clitics, Portuguese language

\section{Introducción}

Pretendemos demostrar cómo se va dignificando en el portugués hablado y escrito de Brasil la posición de los clíticos en la frase; nos servirá para ello la figura de Jorge Amado (1912-2001) que a lo largo de su extensa obra manifiesta una fidelidad lingüística incontestable respecto a la lengua de su país.

Sabido es que en la actualidad la colocación de los pronombres átonos en oraciones afirmativas e imperativas es diferente en Portugal y Brasil. Esa particularidad sintáctica generó encendidas polémicas durante todo el siglo XIX y parte del XX entre los principales escritores y filólogos de ambos lados del Atlántico. 


\section{Origen de la polémica}

Es evidente que cualquier literatura que en principio era colonial y que posteriormente ha devenido en algo genuino, presenta algunos trazos de la metrópoli, del mismo modo que la lengua en la que se expresa -lengua transportada y que con el genio propio del país dominado ha dado un estilo particular y un enfoque diferente-. Ése es el caso de Brasil: no podemos desligar la lengua y la literatura brasileñas en sus inicios, de la portuguesa.

Los historiadores consideran que la literatura brasileña comenzó en el siglo XVI (entre otros, Stegagno 1981), pero esta afirmación solamente es veraz si se confunde la historia literaria del Brasil y la historia de la literatura brasileña. El concepto de literatura brasileña presupone la existencia en este país de una forma de civilización original. El largo proceso de esta conciencia comprende la búsqueda de una idiosincrasia específica y posteriormente su reconocimiento.

La tradición portuguesa durante los siglos XVI y XVII es incuestionable: sobresalen el padre José de Anchieta (1534-1597), Gregório de Matos Guerra (16331696) y el padre António Vieira (1608-1697).

A finales del siglo XVII surge una serie de escritores formados en Coimbra y oriundos de Minas Gerais que dan una nueva visión a la producción literaria que se hacía en Brasil. Agrupados bajo el nombre de "escola de Minas Gerais" representan el inicio de la literatura brasileña. Son conscientes de que pertenecen a una naciente nación con particularidades propias diferentes de las portuguesas (Cláudio Manuel da Costa, Alvarenga Peixoto, Silva Alvarenga y Tomás Gonzaga).

La incipiente idea de la independencia se ve truncada súbitamente cuando la familia real se traslada a Rio de Janeiro huyendo de la invasión napoleónica de Portugal (1808). Ahora, la colonia deviene en metrópoli. Brasil se abre al mundo. El hecho de tener una corte estimuló la vida intelectual del país. Tras la independencia en 1822, Brasil comienza su propia andadura y bajo el signo total del Romanticismo se inicia la verdadera literatura brasileña con la publicación en 1836 de Suspiros poéticos e Saudades de Gonçalves de Magalhães (1811-1882).

A partir de este momento, Brasil buscó su propio camino. No lo hizo, obviamente, sin la influencia de otras culturas o movimientos literarios como ha sucedido en cualquier literatura, aunque sí partiendo de sus propios motivos. Y así, la producción literaria brasileña ha seguido hasta la actualidad su propia ruta paralela a la de las grandes literaturas mundiales. En ese recorrido hasta llegar a Jorge Amado, recordaremos a António Gonçalves Dias (1823-1864), considerado como el poeta más grande del Romanticismo de Brasil. En prosa sobresalió José de Alencar (1829-1877). El Realismo brasileño tuvo a Joaquim Manuel de Macedo (1820-1882) como máxima figura.

El periodo que va de 1875 a 1922 se caracteriza por una riqueza y una diversidad en el aumento de la producción literaria, que testimonian la maduración de la cultura y literatura brasileñas: aquel romanticismo fue sucedido por el realismo y el naturalismo y en la poesía reinaban las tendencias parnasiana y simbolista. Di- 
chos movimientos poéticos no fueron otra cosa que una preparación para la total ruptura que iba a acontecer en los inicios del siglo siguiente. Ruptura que supuso el verdadero inicio de la literatura brasileña, porque, a pesar de utilizar motivos autóctonos en el contenido, la forma seguía siendo la portuguesa: el léxico y la sintaxis utilizados no acababan de romper con la tradición gramatical de Portugal. La situación cambió a partir de 1922.

El primer tercio del siglo XX fue protagonista de una serie de cambios para la historia de la humanidad que mudaron de forma radical la concepción de la vida en todos sus aspectos: la Primera Guerra Mundial, la Revolución Rusa, factores que anunciaban la crisis económica de 1929, la gestación de los fascismos europeos... por otra parte el psicoanálisis de Freud, la eclosión del cine como nuevo medio de comunicación... en lo literario, Kafka y Joyce revolucionaron la técnica de la novela... y podríamos seguir.

Todas estas circunstancias y alguna más, provocaron que las artes -pintura, escultura, teatro, narración y poesía- se lanzasen a la búsqueda de una nueva expresión cuyo rasgo común será destruir la realidad y crear otra nueva: la palabra como creación artística toma un nuevo sentido. De una parte se intenta llegar a lo que se entiende como "arte puro", cada arte con sus medios más elementales y más propios; de otra, se descoyunta la expresión heredada y se experimenta.

En Brasil, todos estos acontecimientos fueron vistos en un primer momento, mediante los ojos de Portugal. Y será en la famosa Semana de Arte Contemporânea de São Paulo, celebrada en 1922, para celebrar el centenario de la independencia, cuando los escritores brasileños se decidan a romper con toda ligazón que venga de fuera y particularmente con todo lo portugués.

Haciendo coincidir la Semana de 1922 con el inicio de una maduración y de una autonomía efectivas de las letras y en general de la sensibilidad brasileñas, se designa con el nombre de Modernismo (en la terminología española corresponde con las Vanguardias) al conjunto de tendencias artísticas brasileñas desde esa fecha hasta nuestros días.

En Europa, a partir de los años 40, tras los desastres de la II Guerra Mundial, los movimientos vanguardistas se pueden dar por finalizados, comenzando una nueva estética vinculada a otras preocupaciones, como fueron el existencialismo, el nihilismo, etc. No obstante, en Brasil, las tendencias vanguardistas continúan hasta la actualidad, si bien muy matizadas con respecto a los presupuestos iniciales de los años 20.

Si nos hemos centrado de manera particular en el Modernismo se debe al hecho de que a Jorge Amado lo hemos de incluir en este período. No obstante, un Modernismo particular, asociado a la tendencia brasileña y después a la suya propia.

A partir de mediados del siglo XX, la literatura brasileña se universaliza, dado que los escritores tratan los temas universales humanos siendo capaces de mostrar en ellos el subconsciente brasileño. El ansia de emanciparse de toda tendencia europea, como ya hemos dicho, provoca que la sintaxis y el léxico utilizados sean 
visiblemente diferentes del portugués padrão. Al rechazar los patrones estilísticos portugueses, los escritores cubren de humor, ironía y parodia las manifestaciones modernistas, pasando a utilizar expresiones coloquiales, muy próximas del habla oral, promoviendo la valoración diferenciada del léxico.

Lo más importante es la actualidad, por eso centran el quehacer literario en la expresión de la vida cotidiana, descrita con palabras del día a día, alejándose de la literatura tradicional, consagrada al patrón culto. No obstante, no existía una imposición de normas y el tratamiento de los temas tampoco estaba unificado.

\section{La questione della lingua}

$\mathrm{Y}$ en este punto es donde Jorge Amado se muestra en todo su esplendor, fiel a su ideario personal en la idea de reflejar el habla real de Brasil. Dejó de lado la disputa que durante años había sido el centro de atención de lingüistas y literatos norma de Portugal frente a uso de Brasil-, centrándose en la realidad lingüística y reflejándola con toda veracidad.

Dos eran los aspectos que debía tratar: el vocabulario propio de su país (y específicamente el de Bahia) y la sintaxis de la oración -particularmente, la colocación de los pronombres clíticos-. En el plano léxico, Mário de Andrade (18391945) fue la figura más representativa del período. Comenzó a abrasileirar la lengua por la introducción de elementos cotidianos. Dicho 'abrasileñamiento' ya se percibía desde los tiempos del gran António de Morais (1755-1824), el autor del Diccionario da Língua Portuguesa (Morais 1789) -considerado uno de los mejores-. Había nacido en Brasil y tuvo que padecer las burlas de los portugueses debido a su manera de hablar. Puso especial empeño al evitar introducir voces no portuguesas y, cuando lo hacía, documentaba la fuente. Las circunstancias eran otras para Jorge Amado y el léxico de la lengua portuguesa entendida como una panlengua a ambos lados del Atlántico, se vio enormemente enriquecido.

Otra bien diferente fue la cuestión de la sintaxis: durante el último tercio del siglo XIX y la primera mitad del XX, la posición de los pronombres átonos en la frase casi se convirtió en un problema nacional. Se 'atentaba contra el idioma patrio', era 'una afrenta' lo que hacían en Brasil... afirmaciones de tal índole marcaron el estudio filológico de Brasil y Portugal. La cuestión llegó a tal extremo que entre 1909 y 1934 se produjo un enfrentamiento entre el gramático portugués Cândido de Figueiredo y el gramático brasileño Paulino de Brito. Cada uno de ellos defendía en la prensa la postura de lo que acontecía en sus respectivos países. Llegó a publicarse el libro O Problema da Colocação de Pronomes, una primera edición en 1911 y una segunda en 1934, autoría del prestigioso portugués (Figueiredo 1934). Dicha obra es la recopilación de gran parte de los artículos aparecidos durante esos años.

Rastreando la obra de Jorge Amado el lector podría pensar que el bahiano estaba ausente de tal polémica, sin embargo, leyendo con atención se observa que Amado utiliza según el registro la postura que más le conviene para lo que trata de 
transmitir. Sus obras presentan unos trazos lingüísticos que se adecuan perfectamente a lo que desea comunicar. En el texto literario normalmente la forma está al servicio del contenido; no ocurre lo mismo en un texto de carácter lingüístico, donde el contenido es la propia reflexión de la forma. En Amado el mensaje transmitido está por encima de la propia reflexión lingüística que percibe un lingüista, Amado utiliza la lengua como instrumento preciso al servicio del mensaje. $\mathrm{Y}$ en cada novela, la lengua utilizada se revela como el vehículo perfecto para la expresión del contenido.

Jorge Amado conoce perfectamente el portugués considerado estándar y los registros que ofrece su lengua para transmitir en boca de sus personajes aquello que nos quiere contar. Nos centraremos en el 'problema' de la colocación de los pronombres átonos.

\section{Jorge Amado}

Y llegados a este punto es ya hora de entrar en el mundo literario de Jorge Amado. Partiremos para nuestro cometido del estudio de tres obras representativas de cada uno de los períodos en los que la crítica ha clasificado su producción:

1. Novelas de Bahia. Denominación dada por el propio escritor. Tienen a Salvador como escenario, son obras comprometidas con la denuncia de las injusticias sociales y de la opresión. En esta tendencia se encuadran: $O$ país do Carnaval, Suor y Capitães da Areia, como las más importantes.

2. Novelas ligadas al ciclo del cacao. También existe la preocupación de denunciar la explotación sufrida por las clases trabajadoras. El escenario es otro: las haciendas del cacao del sur de Bahia, campo de conflictos sociales que provienen de la oposición entre el trabajador rural y el exportador de cacao. Esta temática predomina en Cacau, São Jorge dos Ilhéus y Terras do sem-fim.

3. Crónicas de costumbres. En este tipo de narrativa, el autor pone énfasis en los diversos aspectos que componen el comportamiento social de los personajes, generalmente vistos en grupo o como símbolos de un grupo. Trabajando también en el escenario de Bahia, el autor narra historias en que malandrines y vagabundos son elevados a la categoría de héroes románticos y folletinescos. Son narrativas líricas como Mar morto y Gabriela, cravo e canela, ésta de 1958, uno de los mayores éxitos editoriales de la literatura brasileña. En esta tendencia se encuadra también la novela A morte e a morte de Quincas Berro d'Água. Esta categoría de crónica de costumbres alberga también las novelas protagonizadas por las grandes heroínas de Jorge Amado. Son, además de Gabriela, los personajes-título de las obras Teresa Batista cansada de guerra, Tieta do agreste, Dona Flor e seus dois maridos. 
Para nuestro particular estudio hemos escogido Capitães da Areia (CA), Terras do sem-fim (TSF) y Gabriela, cravo e canela (GCC) como representantes respectivas de los tres períodos antes especificados ${ }^{1}$. En 1981, escribía Gladstone Chaves de Melo (pág. 132) las siguientes palabras: "Poucos assuntos gramaticais da língua portuguesa têm feito correr tanta tinta e têm despertado tantas questões como este da colocação dos pronomes pessoais átonos". Dicha cuestión sirvió, y en cierto modo continúa sirviendo, a aquellos que defienden una supuesta "lengua brasileña". En realidad, el asunto está ligado a la historia de la propia lengua portuguesa, mal explicada en los años posteriores a la independencia de Brasil, o quizás mal entendida a propósito para justificar una norma propia en un nuevo país. La cuestión desembocó en los defensores y los detractores de la colocación de los pronombres átonos a la portuguesa y a la brasileña.

Intentaremos desgranar algunos puntos que pudieron provocar en el portugués de Brasil que la sintaxis de los pronombres átonos fuese diferente de la aplicada en Portugal.

\section{Los clíticos y su historia}

Salvo cuando funcionaban como sujeto o iban precedidos de preposición, los pronombres personales latinos perdieron la tonicidad (que poseían en todos los casos) y se hicieron clíticos (es decir, se colocaban delante o detrás de una voz tónica, normalmente el verbo, con el que, desde el punto de vista fonético, forman una palabra). Como resultado de este proceso, las lenguas románicas desarrollaron dos tipos de pronombres personales: tónicos -yo, tú, él, mí, etc.- y átonos -lo, la, le, se, nos, etc.-

Parece ser que la atonicidad de esas nuevas formas pronominales fue la causa de que se colocasen en una posición determinada. En principio, el tonema de la frase románica permitía que el pronombre se antepusiese (proclisis) o pospusiese (enclisis) al verbo; fue una regla común en el período medieval en los idiomas romances. Posteriormente, actuó el énfasis como elemento vertebrador de la oración. Dicho énfasis pretendía poner de relieve a un elemento de la oración. Si la frase es afirmativa o imperativa, se realza el verbo y el pronombre átono que lo acompaña se coloca detrás; si la frase es negativa o subordinada, se enfatiza la negación o la partícula subordinante, provocando que el pronombre aparezca al lado de dichas palabras.

Para el castellano, dicho énfasis dejó de funcionar a partir del Siglo de Oro (excepto con el imperativo afirmativo) y no era raro escuchar frases como:

"Sentáronse y sentéme" (Quevedo 1994:75) o

\footnotetext{
${ }^{1}$ Las nombraremos de ahora en adelante por estas siglas.
} 
“Habrále Inés concertado con la llave del favor” (Lope de Vega 1985:137).

Desde entonces, la oración española se articula tal y como la conocemos hoy (Penny 1993:137-138).

En el caso de la lengua portuguesa, el tonema enfático deviene en una regla sintáctica mantenida hasta la actualidad. Veamos unos ejemplos del propio Jorge Amado: "O capitão João Magalhães encostou-se na amurada e viu o casario de construção antiga, as torres da igreja." (TSF, pág. 15), donde se enfatiza el verbo, mientras que en "-Não se meta, por favor..." (TSF, pág. 235) se enfatiza la negación y por tanto, el adverbio atrae al pronombre.

En la misma obra, en la página 214 leemos: “-É verdade que se coloca quanto cacau haja..."; frase en la que se enfatiza el sujeto de la oración principal -bajo la forma de una oración completiva-, por tanto la conjunción 'que' atrae al pronombre átono 'se'.

En Brasil, los pronombres átonos que no aparecían en una oración negativa o subordinada fueron adquiriendo un carácter tónico que no poseían en Portugal. Y así, al ser elementos autónomos, podían desplazarse con mayor facilidad que en el padrão portugués. La oración interrogativa "-Lhe roubaram alguma coisa, senhor?" (CA, pág. 142), sería dicha del siguiente modo por un portugués: “Roubaram-lhe alguma coisa, señor?"

Llegan a ser hasta tal punto tónicas que aparecen sin aglutinar incluso con formas verbales impersonales, tales como el infinitivo y el gerundio:

-Pode jogar essas roupas fora. Maria José depois vai lhe trazer roupa... (CA, pág. 123)

-Eu estou querendo te dar um conselho... [...] (TSF, pág. 212)

-Vou the reservar lugar no primeiro banco. (GCC, pág. 15)

La tonicidad brasileña de esos pronombres ha tenido diferentes explicaciones, algunas bastante ridículas. Creemos que la filóloga Rebecca Posner, carente de sentimentalismos portugueses o brasileños, es la que mejor resume y explica la cuestión. Para ella (1998:214-223), es la criollización del portugués la que supone la diferente colocación de los pronombres. Estudios sobre los criollos de todas las lenguas afirman que las bases lingüísticas indígenas que se solapan a la lengua ajena (en este caso el portugués) carecen de formas pronominales átonas. Los tres grupos de lenguas que han influido en el portugués cuando fue llevado a Brasil son las lenguas bantú africanas ${ }^{2}$, las lenguas nigero-congoleñas -especialmente el yo-

\footnotetext{
${ }^{2}$ Procedentes de las zonas donde hoy se sitúan Angola y Mozambique. Los esclavos de estas antiguas colonias fueron llevados al sur de Brasil.
} 
$\mathrm{ruba}^{3}$ - y las lenguas tupí propias de Brasil. En ninguna de ellas se observa un pronombre personal átono. Otra razón que apoya dicha hipótesis está en el portugués hablado en África: en Angola, Mozambique o São Tomé e Príncipe se ha reparado en el mismo hecho, los pronombres son colocados normalmente delante del verbo, debido a su tonicidad. En dichos países existen criollos de base léxica portuguesa pero sintaxis bantú.

La cuestión es tan evidente que se llega a prescindir del pronombre de CD 'o/a' y del CI 'lhe' sustituyéndose por el tónico personal de sujeto:

-A gente quer ele vivo. Para judiar. (GCC, pág. 277)

-[...] É no primeiro andar. Diz a ele que estou esperando. (CA, pág. 45);

Mientras que el uso portugués sería "A gente quere-o vivo" y "Diz-lhe que estou esperando". Las estructuras brasileñas corresponderían en español a una estructura del tipo 'La gente quiere a él vivo', 'Di a él que estoy esperando', siguiendo el orden normal de la frase románica $[\mathrm{S}+\mathrm{V}+\mathrm{C}]$ cuando $[\mathrm{C}]$ es un pronombre tónico.

\section{La fidelidad lingüística}

Explicada la cuestión, cabe entrar en un plano sociolingüístico del 'problema'. La oralidad brasileña reproduce las estructuras tónicas y por tanto proclíticas en cualquier situación, incluso en el lenguaje cuidado. Las gramáticas actuales ya acogen en su seno las reglas brasileñas como propias, con lo que no debería suscitar problemas. No obstante, la gramática prescriptiva portuguesa, de grande peso en Brasil durante siglos, continúa actuando en ciertos contextos, produciéndose:

a) Situaciones de hipercorrección. Repárese en las siguientes oraciones subordinadas temporales:

[...] quando Glória persignou-se sorridente em sua janela amaldiçoada, ... (GCC, pág. 10)

Quando, de volta do bar, sentava-se Gabriela para o almoço, vinha ele roçar-se em suas pernas, a ronronar. (GCC, pág. 180)

O bien en la negativa que se apunta a continuación:

-Pagamos bem, capitão. O senhor não vai-se arrepender. (TSF, pág. 182)

\footnotetext{
${ }^{3}$ Los esclavos nigerianos fueron llevados a Bahia.
} 
b) Situaciones de colocación a la portuguesa en medio de un texto popular. En el siguiente párrafo observamos un uso común y repentinamente, en la frase final, tres verbos con sus correspondientes pronombres colocados tal y como especifica la norma portuguesa:

Hoje é outra mulher a sua mulher. Tocara música para ele, se entregara com paixão. Parece morta nos seus braços... APERTA-A mais, PREPARA-SE para TÊ-LA novamente. [...] (TSF, pág. 104)

Y en la ubicación consciente de esos pronombres es donde Jorge Amado muestra su sapiencia, su fidelidad lingüística. Reproduce todas esas situaciones en sus novelas, y las reproduce partiendo de su ideario, de la emancipación de lo europeo. La naturalidad del texto brasileño se observa en ejemplos como:

-No quarto te digo. Me mostre onde é. (CA, pág. 46); O resfolegar das máquinas lhes deu de repente a certeza de que partia [...] (TSF, pág.15)

-Para o mês eu volto, meu amor, trago os meninos. E você vai ficar boa... O médico me disse... (TSF, pág. 16)

-Pai Jeremias, me sucedeu uma desgraça... (TSF, pág. 122)

-Me escreva. Me escreva... (TSF, pág. 17)

-Não estou gostando de uma coisa, está me preocupando. (GCC, pág. 202)

Y es que, tal y como afirmó el gramático Antônio Houaiss (1985:133), si los escritores brasileños -y entre ellos Jorge Amado- continuasen utilizando la 'lengua neutra' que aprendieron en la escuela, sería imposible que pudiesen "fazer viver, na sua literatura, seus personagens nordestinos".

De todos modos, y como anunciábamos líneas arriba, el peso de la gramática prescriptiva continúa produciendo un décalage, ya que muchos autores en registros cultos -especialmente literarios- colocan los pronombres según la costumbre portuguesa. Este hecho ralentiza la legitimación brasileña en torno a la colocación de los clíticos.

\section{Bibliografía}

AMADO, Jorge (s.d.): [TSF] Terras do Sem-Fim. Lisboa: Edição "Livros do Brasil".

AmADO, Jorge (1992): [CA] Capitães da Areia. Mira Sintra: Publicações EuropaAmérica [ $9^{\mathrm{a}}$ edição].

AMADO, Jorge (1998): [GCC] Gabriela, cravo e canela. Rio de Janeiro: São Paulo, Record [79 edição].

CÂMARA JR., J. Mattoso (1977): Dicionário de Lingüistica e Gramática. Petrópolis, RJ: Editora Vozes Ltda. [16 ${ }^{\mathrm{a}}$ edicão 1992].

Figueiredo, Cândido de (1934): O Problema da Colocação de Pronomes. Lisboa: Livraria Clássica Editora [ $6^{\mathrm{a}}$ edição]. 
HoUAISS, Antônio (1985): O português no Brasil. Rio de Janeiro: EBRADE.

LOPE DE VeGA, Félix (1985): El Caballero de Olmedo. Madrid: Cátedra [Obra escrita entre 1625 y 1632$]$.

Melo, Gladstone Chaves de (1981): Iniciação à Filologia e à Lingüística portuguesa. Rio de Janeiro: Ao Livro Técnico [Reimpressão 1984].

Morais SiLVA, António de (1789): Diccionario da Lingua Portuguesa composto pelo padre D. Raphael Bluteau, reformado e acrecentado por Antonio de Moraes Silva, natural do Rio de Janeiro. Lisboa, na Of. de Simão Tadeo Ferreira [Se sigue publicando en la actualidad muy ampliado y revisado].

PENNY, Ralph (1993): Gramática Histórica del Español. Barcelona: Editorial Ariel [2 ${ }^{\mathrm{a}}$ reimpresión 2001].

POSNER, Rebecca (1998): Las lenguas romances. Madrid: Cátedra.

QUEVEDO, Francisco de (1994): Historia de la vida del Buscón llamado don Pablos. Barcelona: RBA Editores [Edición original de 1626].

Stegagno Picchio, Luciana (1981): La littérature Brésilienne. Paris: Presses Universitaires de France. 